\title{
Staphylococcus aureus-serine protease-like protein B (SplB) activates PAR2 and induces endothelial barrier dysfunction
}

Arundhasa Chandrabalan ${ }^{1}$, Pierre E Thibeault ${ }^{1}$, Bojan Smiljanov ${ }^{2,}{ }^{3}$, Laura A Mittmann ${ }^{2,}{ }^{3}$, Stefanie Deinhardt-Emmer ${ }^{4}$, Maria Nordengrün ${ }^{5}$, Jawad $\mid q b a l^{5}$, Daniel M Mrochen ${ }^{5 \#}$, Bishwas Chamling ${ }^{6,7}$, Bernhard H Rauch ${ }^{8}$, Christoph A Reichel ${ }^{2,3}$, Rithwik Ramachandran ${ }^{1}$, Barbara M Bröker $^{5}$, Murty N Darisipudi $5^{\star}$

${ }^{1}$ Department of Physiology and Pharmacology, Schulich School of Medicine and Dentistry, University of Western Ontario, London, Ontario, Canada

${ }^{2}$ Department of Otorhinolaryngology, University Hospital, Ludwig-Maximilians-University Munich, Munich, Germany

${ }^{3}$ Walter Brendel Centre of Experimental Medicine, University Hospital, Ludwig-MaximiliansUniversity Munich, Munich, Germany

${ }^{4}$ Institute of Medical Microbiology, Jena University Hospital, Jena, Germany

${ }^{5}$ Department of Immunology, Institute of Immunology and Transfusion Medicine, University Medicine Greifswald, Greifswald, Germany

${ }^{6}$ Department of Cardiology, Internal Medicine B, University Medicine Greifswald, Greifswald, Germany

${ }^{7}$ DZHK (German Centre for Cardiovascular Research), Partner Site Greifswald, Germany

${ }^{8}$ Department of General Pharmacology, Institute of Pharmacology, University Medicine Greifswald, Greifswald, Germany

"Present address: ZIK plasmatis, Leibniz Institute for Plasma Science and Technology e.V. (INP), Greifswald, MV, 17489, Germany

\section{${ }^{*}$ Correspondence:}

Dr. V.S. Narayana Murty Darisipudi

Venkata.darisipudi@uni-greifswald.de

\section{Address:}

Department of Immunology

Institute of Immunology and Transfusion Medicine

University Medicine Greifswald

F. Sauerbruchstr. DZ 7

17475 Greifswald, Germany

Keywords: Staphylococcus aureus, SplB, endothelial damage, proteinase-activated receptor 2, PAR2, G-protein-coupled receptors, cytokines

Running title: SpIB mediates endothelial inflammation and barrier disruption via PAR2 


\begin{abstract}
Staphylococcus aureus ( $S$. aureus) is a major cause of life-threatening systemic infection in humans. To cause blood stream infections such as sepsis and endocarditis, the bacteria must overcome the host's endothelial barrier. The serine protease-like proteins (Spls) of $S$. aureus are known to contribute to pneumonia and allergic airway inflammation in animal models, but their role in endothelial damage is unknown. Here we demonstrate that SplB induces proinflammatory cytokine release in primary human vascular endothelial cells (HUVECs) in vitro. Mechanistically, we show that SpIB selectively cleaves and activates human proteinase-activated receptor-2 (PAR2), and induces biased signaling via $\mathrm{Ga}_{13}, \mathrm{Ga}_{\mathrm{i1/0B}}(\mathrm{NF}-\mathrm{k} \beta)$, and $\beta$-arrestin-1/-2. This activation did not trigger $\mathrm{Ga}_{\mathrm{q} / 11}$-mediated calcium release nor ERK phosphorylation. Inhibition of PAR2 in HUVECs reduced the SplB-mediated cytokine release. Intravital microscopy of cremaster muscles in mice demonstrated that administration of SplB causes microvascular leakage. Genetic deletion of PAR2 in mice or neutralization of SplB with a monoclonal antibody preserved the endothelial barrier. This study identifies PAR2 as a receptor and substrate for SplB and highlights its role in mediating endothelial damage.
\end{abstract}




\section{Introduction}

Staphylococcus aureus ( $S$. aureus) is a ubiquitous Gram-positive bacterium that transiently or persistently colonizes the human nares and skin $(1,2)$. $S$. aureus causes many diseases ranging from soft tissue infections to systemic infections such as pneumonia, endocarditis, and sepsis. Systemic $S$. aureus infections are often associated with high morbidity and mortality. In addition, over the decades, $S$. aureus has developed resistance to several antibiotics and poses a challenge to clinicians and a burden to the global health care systems (3-7).

The endothelial barrier offers the first line of defense against invading pathogens. $S$. aureus secretes a wide range of virulence factors, toxins, and proteases that interact with various receptors on the endothelium (8-10), enabling invasion of host tissues by disruption of endothelial barrier. $S$. aureus interaction with the endothelium leads to the production of proinflammatory cytokines and triggers cell death $(11,12)$. Pore-forming toxins, leucocidin ED (LukED) and $\mathrm{y}$-Hemolysin $\mathrm{AB}$ (HIgAB) induce endothelial permeability via activating the Duffy antigen receptor for chemokines (DARC), which results in organ dysfunction and death in mice (13). Cell wall components of $S$. aureus, peptidoglycan $G$ and lipoteichoic acid are also potent inducers of endothelial damage (ED) (14). It is also well known that proteases from both host and pathogen contribute to barrier disruption via interacting with a four-member family of $G$ protein-coupled receptors (GPCRs) called proteinase-activated receptors (PARs, PAR1-4) (15, 16).

PARs are widely expressed in various cell types, including endothelial cells (17-19). PARs are activated through proteolytic cleavage of the receptor $\mathrm{N}$-terminus at specific sites and unmasking of a tethered ligand (20-23). Activation of PARs leads to G-protein activation, $\beta$ arrestin recruitment and triggering of intracellular cascades via effectors including extracellular signal-regulated kinase (ERK-1/2) mitogen-activated protein kinases (MAPK) and the nuclear factor- $\mathrm{\beta} \beta$ (NF-k $\beta$ ). This induces the release of cytokines and chemokines, thereby recruiting leukocytes to promote the innate immune response $(24,25)$.

PARs are also known as central players in allergy. PAR activation in epithelial cells of patients with inflamed airways promotes the induction of allergic asthma (26-30). Activation of PAR2 on mast cells induces degranulation, while eosinophils respond with superoxide production (31). PARs can be activated by various proteases like thrombin (PAR1, 3 and 4) and mast cellderived tryptase (PAR2) (32) that are generated following injury or infection. Pathogen-derived proteases such as allergens of house dust mite (Der p 1, -3, -9) and mold Penicillium citrinum (Pen c 13) also activate PAR2 $(33,34)$. The activation of PAR2 on epithelial cells and 
macrophages by serine proteases from German cockroach feces extract also contributes to airway hypersensitivity (34).

The species $S$. aureus harbors a broad spectrum of extracellular virulence factors, among them several proteases, namely aureolysin, V8 protease (SspA), the staphopains A and B (ScpA and $\mathrm{SspB}$ ), the exfoliative toxins $A$ and $B$, and the serine protease-like proteins (Spls) $A-F(35,36)$. Extracellular proteases of $S$. aureus are known to play an important role in the pathogenesis (37-42). For example, the V8 protease and staphopains of $S$. aureus alter the integrity of the airway epithelial barrier, thereby promoting lung damage (43). Less is known about the functions of the serine protease-like proteins (Spls). Spls promoted the dissemination of $S$. aureus in a rabbit model of pneumonia (39), and SpIA has been reported to cleave mucin-16 (44). We recently reported that the Spls have allergenic properties in humans (SpIA, SplB, SpID, SplE) and mice (SpID) $(37,40)$. Administration of SpID to the trachea of mice induced allergic asthma, which was associated with an increased number of PAR2-positive infiltrating cells in the lungs compared to control animals (37). These studies highlight the interaction of Spls with the host immune system, though host substrates for the Spls remain elusive.

Here we studied the regulation of the endothelial barrier by $S$. aureus SplB. We found that SplB induces the production of proinflammatory cytokines in primary endothelial cells in vitro. Importantly we find that SpIB mediated inflammation in endothelial cells is dependent on the cell surface GPCR PAR2, which we identify as a cellular protease sensor and host substrate of SplB. In mice, administration of SplB leads to microvascular damage in a PAR2 dependent manner. Our results indicate an important role for $S$. aureus-SplB in triggering endothelial inflammatory responses and identify PAR2 antagonisms as a potential therapeutic target in S. aureus infection-associated pathologies. 


\section{Material and methods}

\section{In vitro experiments with HUVECs}

Primary human umbilical vein endothelial cells (HUVECs) were isolated by collagenase treatment as previously described (45). The investigation conforms to the principles outlined in the Declaration of Helsinki for the use of human tissues (46). Informed consent was obtained from all the mothers donating umbilical cords in accordance with the responsible Ethics Committee. Cells were maintained at $37^{\circ} \mathrm{C}$ and $5 \% \mathrm{CO}_{2}$ in $\mathrm{MCDB} 131$ medium (Pan Biotech) supplemented with $10 \%$ fetal calf serum (FCS, Life Technologies), $1 \mathrm{ng} / \mathrm{mL}$ bovine fibroblast growth factor (bFGF), $0.1 \mathrm{ng} / \mathrm{mL}$ epidermal growth factor (EGF), $1 \mu \mathrm{g} / \mathrm{mL}$ hydrocortisone, $1 \%$ penicillin and streptomycin, $2 \mathrm{mM}$ Glutamine, $500 \mu \mathrm{L}$ heparin, and $2 \mathrm{~mL}$ endothelial cell growth supplement (ECGS). All other supplements were obtained from Gibco (Thermo Fisher Scientific). The cells were passaged 3-5 times before use. For stimulation experiments, cells were seeded into either in 12- or 24-well plates at a density of $2.5 \times 10^{5}$ cells $/ \mathrm{mL}$ and serumstarved overnight in medium containing only $1 \%$ FCS. On the following day, cells were incubated in medium containing $2 \%$ FCS with or without the PAR2 negative allosteric modulator (AZ3451, Sigma Aldrich) or a NF-k $\beta$ inhibitor (Bay11-0782, Invivogen) 45 minutes before stimulation with recombinant SpIB or SLIGRL-NH $\mathrm{N}_{2}$ (PAR2 activating peptide, PAR2-AP, Tocris, WiesbadenNordenstadt, Germany). Cell-free supernatants were collected and analyzed for cytokines by ELISA or multiplex assay (LegendPlex ${ }^{\mathrm{TM}}$ ) according to the manufacturer's instructions.

\section{Immunofluorescence}

To determine the effect of SplB in vitro, we used multiorgan tissue flow (MOTiF) biochips (Microfluidic ChipShop $\mathrm{GmbH}$, Jena, Germany). The composition of the model and the perfusion of the system was described elsewhere (47). Briefly, HUVECs were seeded at a density of $2.7 \mathrm{x}$ $10^{5} / \mathrm{cm}^{2}$ on the endothelial side of the chip and grown in endothelial cell growth medium (PromoCell, Heidelberg, Germany). On the opposite chamber, $2.7 \times 10^{5} / \mathrm{cm}^{2}$ of $\mathrm{NCl}-\mathrm{H} 441$ (ATCC, Manassas, USA) were cultured in RPMI-1640 (Lonza, Cologne, Germany) supplemented with 10 \% FCS. In addition, monocyte-derived macrophages were seeded on the $\mathrm{NCl}-\mathrm{H} 441$ cell layer with a density of $0.9 \times 10^{5}$ macrophages $/ \mathrm{cm}^{2}$. The alveolus-on-a-chip was stimulated with $100 \mu \mathrm{g} / \mathrm{mL}$ SplB for $6 \mathrm{~h}$. After cutting the membranes, endothelial cell monolayer was washed with PBS (containing $\mathrm{Ca}^{2+}$ and $\mathrm{Mg}^{2+}$ ) and blocked with $3 \%$ normal donkey serum (Dianova, Germany) containing $0.1 \%$ Triton X-100 (Sigma-Aldrich, Germany). Cells were incubated over night with the primary antibodies to vascular endothelial cadherin (VE-cadherin) (BD Biosciences, Heidelberg, Germany), endothelial cadherin (E-cadherin) (BD Biosciences, Heidelberg, Germany), CD68 (BD Biosciences, Heidelberg, Germany), and intracellular 
adhesion molecule 1 (ICAM-1) (Invitrogen, Carlsbad, CA, USA). Following several wash steps, membranes were incubated for $30 \mathrm{~min}$ at RT with DAPI (Life Technologies) and the following secondary antibodies: donkey immunoglobulin (lg)G anti-mouse $\lg$ G-Cy3, donkey $\lg G \mathrm{~F}(\mathrm{ab}$ ') anti-rabbit IgG-AF488 and donkey anti-goat IgG-Cy5 (all obtained from Dianova, Hamburg, Germany). Images were acquired using an AXIO Observer Z1 fluorescence microscope (Carl Zeiss AG, Jena, Germany).

\section{PAR cleavage assays with SpIB}

PAR-reporter cells were generated as previously described (48-50). Briefly, Chinese Hamster Ovary $(\mathrm{CHO})$ cells were stably transfected with constructs expressing human PAR1, PAR2 or PAR4 tagged with an N-terminal nano luciferase (nLuc) and a C-terminal enhanced yellow fluorescent protein eYFP. Cells were routinely cultured in Ham's F-12 Nutrient Mix with 1 mM sodium pyruvate, $100 \mathrm{U} / \mathrm{mL}$ penicillin, $100 \mu \mathrm{g} / \mathrm{mL}$ streptomycin, $1 \mathrm{mM} \mathrm{L}$-glutamine, and 10\% heat-inactivated fetal bovine serum (FBS, Gibco, ThermoFisher Scientific) and $600 \mu \mathrm{g} / \mathrm{mL}$ G418 sulfate (Invitrogen, ThermoFisher Scientific). The PAR-reporter cells were seeded in a 96-well culture plate at a density of $1 \times 10^{4}$ cells per well and cultured for $48 \mathrm{~h}$. Cells were rinsed three times with Hanks' Balanced Salt Solution (HBSS, Gibco ThermoFisher Scientific) containing $\mathrm{CaCl}_{2}$ and $\mathrm{MgCl}_{2}$ and incubated with $100 \mu \mathrm{L} \mathrm{HBSS}$ at $37^{\circ} \mathrm{C}$ for 15 minutes. $50 \mu \mathrm{L}$ of the supernatant from each well was transferred to a 96-well plate to obtain the basal luminescence. The cells were then treated with SplB $(5 \mu \mathrm{g} / \mathrm{mL})$ or increasing concentrations of human plasma thrombin (PAR1 and PAR4 agonist, Calbiochem-EMD Millipore) or porcine trypsin (PAR2 agonist, Type IX-S, 13000-20000 BAEE units/mg protein, Sigma Aldrich) or HBSS in a volume of $50 \mu \mathrm{L}$ for 15 minutes at $37^{\circ} \mathrm{C}$. $50 \mu \mathrm{L}$ of the supernatant was removed from treated wells and the luminescence values were again recorded on a plate reader (Mithras LB 940, Berthold Technologies) in the presence of the nano luciferase substrate furimazine ( $2 \mu \mathrm{L} / \mathrm{mL}$, Promega).

\section{Calcium signaling}

Calcium mobilization after PAR activation was measured as previously described with some modifications (51). Briefly, HEK293 cells were maintained in Dulbecco's Modified Eagle's Medium (DMEM, Gibco, Thermoscientific) supplemented with $1 \mathrm{mM}$ sodium pyruvate, $100 \mathrm{U} / \mathrm{mL}$ penicillin, $100 \mu \mathrm{g} / \mathrm{mL}$ streptomycin, $2 \mathrm{mM} \mathrm{L}$-glutamine, and 10\% heat-inactivated FBS. Cells were seeded at a density of $2 \times 10^{4}$ cells per well in a poly-D-lysine coated 96-well black cell culture plate and cultured for $48 \mathrm{~h}$. The cells were rinsed twice with phosphate-buffered saline solution (PBS, Invitrogen) and incubated with Fluo-4 NW calcium indicator (50 $\mu \mathrm{L}$ per well, Life Technologies) for 30 minutes at $37^{\circ} \mathrm{C}$ in the dark and for an additional 15 minutes at RT. Changes in intracellular fluorescence was measured as an indicator of elevated cytoplasmic 
$\mathrm{Ca}^{2+}$ using a microplate reader FlexStation3 (Molecular Devices). The baseline fluorescence values were recorded for $20 \mathrm{~s}$ before the addition of agonists and fluorescence spectra were recorded for an additional $180 \mathrm{~s}$. In some experiments, cells were pre-treated with $\mathrm{Ga}_{\mathrm{q} / 11}$ inhibitor (YM-254890, $1 \mu \mathrm{M})(52)$ for 10 minutes at RT before treating with agonists. Calcium ionophore (A23187, $6 \mu \mathrm{M}$, Sigma-Aldrich) was used as a control in all experiments to establish proper dye loading and to determine the maximum response possible in each plate of cells.

\section{G protein and $\beta$-arrestin recruitment assays}

Recruitment of Ga12, 13, i1 or oB, and $\beta$-arrestin-1 or -2 was measured using bioluminescence resonance energy transfer (BRET) assay $(53,54)$. Briefly, to measure $\mathrm{Ga12}$, 13 , i1 or oB recruitment, HEK293 cells $\left(2 \times 10^{4}\right.$ cells per well) were transiently transfected using $X$ tremeGENE $^{\text {TM }} 9$ (Sigma) with plasmids encoding eYFP tagged PAR2 (PAR2-eYFP) (50) and renilla luciferase (rluc8) tagged Ga subunits (eYFP:rluc8, 10:1 ratio) in an opaque white 96-well plate. pcDNA5/FRT/TO-Ga $\alpha_{12 / 13 / 1 / \mathrm{oB}}-\mathrm{RLuc8}$ plasmids were a gift from Dr. Bryan Roth [Addgene

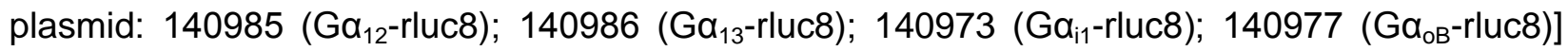
(55). $48 \mathrm{~h}$ after transfection, the culture medium was replaced with HBSS $(60 \mu \mathrm{L})$ and coelenterazine-h substrate (10 $\mathrm{L}, 50 \mu \mathrm{M}$, Nanolight Technology) was added to the plate. eYFP $(530 \mathrm{~nm})$ and rluc8 $(470 \mathrm{~nm})$ emissions were measured for $240 \mathrm{~s}$ on a FlexStation3 plate reader immediately after the addition of $30 \mu \mathrm{L}$ trypsin (100 nM), SplB $(5 \mu \mathrm{g} / \mathrm{mL})$ or HBSS injected using the integrated automatic pipettor.

To measure $\beta$-arrestin-1 or -2 recruitment, HEK293 cells were transiently transfected using calcium phosphate with plasmids encoding PAR2-eYFP and rluc tagged $\beta$-arrestin-1 or -2 (eYFP:rluc, 10:1 ratio) for 24 h. $\beta$-arrestin-1 and -2 plasmids were a kind gift from Dr. Michel Bouvier. Cells were transferred to a white 96-well plate at a density of $2.5 \times 10^{4}$ cell/mL and cultured for an additional $24 \mathrm{~h}$ before incubation with HBSS alone or different concentrations of trypsin $(10 \mathrm{nM})$ or SpIB $(5 \mu \mathrm{g} / \mathrm{mL})$ for 20 minutes at $37^{\circ} \mathrm{C}$. The rluc substrate coelenterazine-h $(5$ $\mu \mathrm{M})$ was added 10 minutes before taking the measurement. Emission of eYFP and luminescence of rluc was measured on a Mithras LB 940 plate reader (Berthold Technologies).

\section{ERK/MAPK Western blot analysis}

PAR2-knockout (KO) HEK293 cells were generated using CRISPR/Cas9 as previously described (53). Western blot analysis of ERK MAPKinase was done as previously described (53). Briefly, HEK293 or PAR2 KO HEK293 cells were seeded at a density of $4 \times 10^{5}$ cells $/ \mathrm{mL}$ in a 12-well plate and serum-starved for $2 \mathrm{~h}$ to reduce basal levels of ERK phosphorylation. Cells were then stimulated with either SpIB $(5 \mu \mathrm{g} / \mathrm{mL})$ or trypsin $(10 \mathrm{nM})$ for 10 minutes. Control wells 
received only buffer (HBSS). Cells were harvested in an NP-40 based lysis buffer supplemented with protease and phosphatase inhibitor cocktail. Proteins in the cell lysates were separated on 4-12\% Bis-Tris precast gels (Invitrogen) in MES buffer, blotted with primary antibody to phosphorylated ERK (pERK; p44/42 Thr202/Tyr204) or total ERK (tERK; p44/42) followed by incubation with HRP-conjugated secondary antibodies (1:1000). Chemiluminescence was measured using ECL detection reagent (GE Healthcare) on an iBright CL1000 (Invitrogen). All antibodies were obtained from Cell signaling Technology, Massachusetts, USA.

\section{SpIB cleavage site on PAR2}

To determine the cleavage site(s) of SpIB on PAR2, a peptide representing the hPAR2 Nterminal domain spanning the tethered ligand region, GTNRSSKGRSLIGKVDGTSHV-NH ${ }_{2}$, was synthesized using Fmoc solid-phase peptide synthesis on a peptide synthesizer (Syrowave, Biotage). The purity of the peptide was $98 \%$ as assessed by analytical reversed-phase HPLCMS. Peptide and enzyme solutions were dissolved and diluted in 25 mM 4-(2-hydroxyethyl)-1piperazine ethanesulfonic acid (HEPES, Fisher Scientific). The peptide (100 $\mu \mathrm{M}$ in a total volume of $100 \mu \mathrm{L})$ was incubated with either trypsin $(10 \mathrm{nM})$ or SplB $(50 \mu \mathrm{g} / \mathrm{mL})$ for 60 minutes at $37^{\circ} \mathrm{C}$. The reaction was terminated by adding ice-cold $0.1 \%$ trifluoroacetic acid (TFA) in $\mathrm{H}_{2} \mathrm{O}$ $(100 \mu \mathrm{L})$ as described previously (56) and subjected to MALDI-MS analysis (AB Sciex 5800 TOF/TOF MS, UWO MALDI MS Facility, Western University). Cleavage sites (//) were identified from any additional $\mathrm{m} / \mathrm{z}$ peaks (peptide fragments) observed in the mass spectrum of the enzyme-treated peptide.

\section{Intravital microscopy of cremaster muscles}

The surgical preparation of the cremaster muscle was performed as described elsewhere (57). Briefly, C57BL/6 WT or PAR2-KO mice were anesthetized with ketamine/xylazine (100 mg/kg ketamine and $10 \mathrm{mg} / \mathrm{kg}$ xylazine; i.p), and the left femoral artery was cannulated in a retrograde manner using a polyethylene-10 catheter (inner diameter $0.28 \mathrm{~mm}$, Portex) for the administration of substances. The right cremaster muscle was exposed through a ventral incision of the scrotum. The muscle was opened ventrally in a relatively avascular zone and spread over the transparent pedestal of a custom-made microscopy stage. Epididymis and testicle were detached from the cremaster muscle and replaced in the abdominal cavity. The muscle was superfused with warm-buffered saline throughout the procedure. Leakage of intravenously applied FITC dextran (Sigma-Aldrich) to the perivascular tissue was analyzed in animals after intrascrotal stimulation with $10 \mu \mathrm{g}$ of SpIB. In selected experiments, animals also received monoclonal antibodies directed against SpIB. All animal experiments were carried out in 
accordance with German animal protection laws and approved by local animal protection authority (Regierung von Oberbayern, Munich, Germany).

\section{Statistical analyses}

The cytokine data in Figure 1 are expressed as mean \pm SD of three independent experiments. The t-test was utilized to determine statistical significance vs control, * $p<0.05$. The luminescence measurements in the PAR cleavage assay are presented as a percentage of the maximum response to thrombin $(3 \mathrm{U} / \mathrm{mL})$ or trypsin $(100 \mathrm{nM})$. The cleavage data are presented as the mean \pm SEM of at least three independent experiments performed in duplicates. Two-way ANOVA was utilized to determine statistical significance relative to the HBSS control, ${ }^{* * *} p<0.001$. BRET ratio (eYFP/rluc) was calculated for each condition, and the net BRET ratios were obtained after normalizing to the buffer condition. The BRET data are represented as mean \pm SEM of at least three independent experiments performed in duplicate. The Western blot analysis data are expressed as ratio pERK to tERK mean \pm SEM of three independent experiments. Two-way ANOVA was utilized to determine statistical significance vs relative response obtained with HBSS in the same cell line, ${ }^{*} p<0.05$. The immunofluorescence data are expressed as mean MFI ratio of VE-Cadherin and ICAM-1 mean \pm SD of three independent experiments. The t-test was utilized to determine statistical significance vs control, * $p<0.05$. The vascular leakage data in mice are expressed MFI of FITC mean \pm SD of 4-5 animals per group. The t-test was utilized to determine statistical significance, ${ }^{*} p<0.05$ SpIB vs. Par2 ${ }^{--}$-SpIB.

\section{Results}

\section{SpIB induces proinflammatory cytokines in primary human endothelial cells}

To assess whether SpIB has the ability to induce endothelial inflammation in vitro, we stimulated primary human umbilical vein endothelial cells (HUVECs) with SpIB for $24 \mathrm{~h}$. As shown in Figure 1, SplB significantly enhanced the interleukin (IL)-6 release and tended to increase the release of TNFa, IL-18, and IL-23.

\section{SplB cleaves PAR2 but not PAR1 and PAR4}

Since PARs are major targets of many bacterial proteases and mediate the production of cytokines in various host cells, including endothelial cells $(58,24)$, we hypothesized that SplB cleaves and activates PARs. To study this, CHO cells expressing nLuc-PAR1-eYFP, nLucPAR2-eYFP, or nLuc-PAR4-eYFP were treated with SpIB and the cleavage of the N-terminal nLuc tag was monitored (Figure 2A). Thrombin (PAR1 and PAR4 activating enzyme) and trypsin (PAR2 agonist) were used as positive controls and cleaved the $\mathrm{N}$-terminal tags over the 
expected range of concentrations (Supplementary Figure 1A-C). Cells treated with HBSS only served as negative controls. As shown in Figure 2A, SplB selectively cleaved PAR2 with no cleavage evident for the PAR1 and PAR4. SpIB $(5 \mu \mathrm{g} / \mathrm{ml})$ displayed significant activity at PAR2 producing a nLuc cleavage signal that was $\sim 20 \%$ of the maximal cleavage of PAR2 elicited by trypsin (100 nM).

\section{SpIB activates $\mathrm{G} \alpha_{13}, \mathrm{G} \alpha_{\mathrm{i} 1 / \mathrm{BB}}$ and $\beta$-arrestin-1/2 recruitment to PAR2 but does not activate $\mathrm{G} \alpha_{\mathrm{q} / 11}$ or MAPK}

Following the observation that SpIB can cleave PAR2, we sought to determine whether this could activate PAR2 signaling. It is known that PAR2 activation by trypsin triggers robust calcium release, which is dependent on the $G \alpha_{q / 11}$ signaling pathway (59). HEK293 cells that endogenously express PAR2 were treated with increasing concentrations of trypsin or SplB as indicated (Figure 2B). As expected, trypsin triggered calcium mobilization from the cells in a dose-dependent manner (Supplementary Figure 2), which was dependent on $\mathrm{Ga}_{\mathrm{q} / 11}$ as inhibition of the latter completely abolished calcium mobilization (52) (Figure 2B). To our surprise, SplB (5 $\mu \mathrm{g} / \mathrm{mL}$ ) did not induce calcium mobilization from the cells (Figure $2 \mathrm{~B}$ ) despite the significant cleavage of the PAR2 N-terminus by this enzyme (Figure 2A). These results demonstrate that SplB does not activate PAR2 signaling via the $\mathrm{Ga}_{\mathrm{q} / 11}$ pathway.

PAR2 like many other GPCRs can couple to multiple signalling effectors including $\mathrm{G}_{12 / 13}$, $\mathrm{G}_{\mathrm{i} 1 / \mathrm{OB}}$ and $\beta$-arrestin-1/2. We assessed recruitment of each of these effectors to PAR2 using a BRET assay. HEK293 cells transiently expressing PAR2-eYFP and rLuc8 tagged G proteins $\left(\mathrm{Ga}_{12}, \mathrm{Ga}_{13}, \mathrm{Ga}_{\mathrm{i1}}\right.$ or $\left.\mathrm{Ga}_{\mathrm{oB}}\right)$ were treated with either trypsin $(100 \mathrm{nM})$ or SplB $(5 \mu \mathrm{g} / \mathrm{mL})$. As observed in previous studies (54), trypsin triggered significant recruitment of all four G-proteins $\mathrm{Ga}_{12}, \mathrm{Ga}_{13}, \mathrm{Ga}_{\mathrm{i1}}$, and $\mathrm{Ga}_{\mathrm{oB}}$ to PAR2, whereas SplB treatment resulted in the recruitment of $\mathrm{Ga}_{13}$, $\mathrm{Ga}_{\mathrm{i} 1}$ and $\mathrm{Ga}_{\mathrm{OB}}$ as indicated by an elevated BRET signal compared to the baseline in HBSS treated controls (Figure 2C, 2D).

Next, we assessed $\beta$-arrestin-1 and/or -2 recruitment to PAR2 using a BRET assay. For this, HEK293 cells expressing PAR2-eYFP and rLuc- $\beta$-arrestin-1 or -2 fusion proteins were treated with either SplB $(5 \mu \mathrm{g} / \mathrm{mL})$ or trypsin $(10 \mathrm{nM})$. As expected, trypsin treatment resulted in the recruitment of $\beta$-arrestin-1 and -2 (Figure 2E). SplB also triggered a significant increase in recruitment of both $\beta$-arrestins (Figure $2 \mathrm{E}$ ) compared to the HBSS control.

In recent work, we demonstrated that PAR2-mediated ERK phosphorylation in HEK293 cells occurs downstream of $\mathrm{Ga}_{\mathrm{q} / 11}$ signaling (59). Nevertheless, we assessed ERK phosphorylation 
following the cleavage of PAR2 by SpIB. HEK293 cells that endogenously express PAR2 or PAR2-KO HEK293 cells were treated with either SpIB or trypsin and p42/44 (ERK) MAPK phosphorylation was assessed by Western blot. SplB did not trigger a significant increase in ERK phosphorylation compared to untreated cells (Figure 2F). In contrast, trypsin activation of PAR2 resulted in a significant increase in ERK phosphorylation compared to untreated controls (Figure 2F). As expected, neither trypsin nor SplB was able to induce ERK phosphorylation in cells lacking PAR2 (Figure 2F). Overall, these data are in line with our observation that SpIB stimulation of PAR2 does not induce $\mathrm{Ga}_{\mathrm{q} / 11}$ mediated signaling.

\section{SpIB induced IL-6 release is dependent on PAR2-NF- $\boldsymbol{\beta} \beta$ signaling cascade}

We next sought to determine whether SpIB triggered cytokine production in endothelial cells was mediated by PAR2. We treated primary HUVECs with SpIB or a PAR2-AP with or without a PAR2 negative allosteric modulator AZ3451 and assessed IL-6 levels in the culture supernatants. Treatment of cells with SpIB induced production of IL-6, while the response to the PAR2-AP was more modest but elevated in comparison to the high basal levels of IL-6 seen in untreated cells (Figure 3A). Inhibition of PAR2 in SplB treated cells lowered the cytokine release to the background level (Figure $3 \mathrm{~A}$ ). It has been reported that some PAR2 activating proteases induce cytokine production via the NF-K $\beta$ pathway (60). In addition, activation of $\mathrm{Ga}_{\mathrm{i} 1 / \mathrm{oB}}$ by PAR2 can activate NF-K $\beta$, leading to IL-6 release. Blockade of NF-K $\beta$ signaling completely abolished the spontaneous and SpIB triggered IL-6 release in HUVECs (Figure 3B), indicating that SpIB induces IL-6 cytokine release in endothelial cells in an NF-Kß-dependent fashion. Since PAR2 activates $\mathrm{Ga}_{\mathrm{i} 1 / \mathrm{OB}}$ in response to SplB, it is likely that IL-6 release here is mediated by $\mathrm{Ga}_{\mathrm{i} 1 / \mathrm{oB}}$.

Taken together, these results show that SpIB selectively cleaves PAR2 and induces the downstream signaling through $\mathrm{Ga}_{13}, \mathrm{Ga}_{\mathrm{i} 1 / 0 \mathrm{~B}}$, and $\beta$-arrestin-1/2 pathway. In addition, SplB action on endothelial cells occurs at least in part through PAR2, and culminates in NF-k $\beta$ activation and cytokine production.

\section{SpIB does not cleave PAR2 at the trypsin cleavage site}

Since SpIB and trypsin activated PAR2 show a partially overlapping signaling profile (Figure 2), we sought to examine whether SpIB cleaves PAR2 at the trypsin cleavage site. To determine this, we synthesized a peptide representing the hPAR2 N-terminal domain spanning the trypsin cleavage site, GTNRSSKGRSLIGKVDGTSHV-NH ${ }_{2}$ (Supplementary Figure 3A), and incubated with trypsin or SpIB for 60 minutes. The digestion mixture was then subjected to MALDI-MS analysis to identify the possible peptide fragments. Consistent with previous findings $(61,60)$, trypsin cleaved the synthetic peptide at the expected $\mathrm{R}^{36} / / \mathrm{S}^{37}$ (major site) and $\mathrm{K}^{34} / / \mathrm{G}^{35}$ sites 
within the 60 minutes reaction time (Supplementary Figure 3B). However, SplB did not cleave this peptide as no peptide fragmentation was detectable (Supplementary Figure $3 \mathrm{C}$ ). This result indicates that the SplB cleavage site on hPAR2 lies outside of this region and needs to be investigated further in future peptide mapping and mutational studies.

\section{SpIB induces endothelial barrier disruption in vitro and in vivo}

Many proteases, bacterial toxins, and cytokines are known to disrupt the endothelial barrier. Previous studies have demonstrated that proteases that activate the PAR2 can also induce endothelial barrier disruption (62). Having demonstrated that SpIB activates PAR2 and induces proinflammatory cytokines in endothelial cells, we asked whether this bacterial protease is able to damage the endothelial barrier. To address this, SpIB-exposed HUVEC monolayers were subjected to immunofluorescence analysis for the expression of VE-cadherin and ICAM-1, two essential components that maintain the integrity of the endothelial barrier. In the SplB treated cells the amount of available VE-cadherin was significantly diminished while ICAM-1 expression was upregulated, resulting in a strong reduction of the mean fluorescence intensity (MFI) ratio between VE-cadherin and ICAM-1 (Figure 4A). This suggests that $S$. aureus SpIB weakens the endothelial barrier integrity. Next, we employed intravital microscopy to observe the integrity of the endothelial barrier in vivo in a mouse model of microvascular leakage (57). Consistent with our observations in vitro, administration of SpIB in mice leads to massive leakage of FITC dextran across the vasculature to the perivascular space in the murine cremaster muscle. Importantly, deficiency of PAR2 or treatment of animals with a SpIB-neutralizing monoclonal antibody before SpIB administration almost completely abolished the SplB effect (Figure 3B). These results demonstrate that $S$. aureus-SpIB induces endothelial barrier dysfunction via PAR2 activation.

\section{Discussion}

Our study demonstrates that one of the extracellular $S$. aureus-serine protease-like proteins (Spls), SplB, induces endothelial dysfunction in vitro and in vivo. Spls are a group of six proteases, namely SpIA to SpIF encoded by the spl operon (63), whose functions are yet to be fully explored. The Spls show high sequence homology among themselves and structural homology to $S$. aureus V8 protease (63). Except for SplA, which cleaves mucin-16 on the human epithelial cells (44), no biologically relevant substrates for Spls have been identified so far. Here we report that SpIB cleaves human PAR2 but not PAR1 and PAR4, which identifies the first biologically relevant and therapeutically tractable substrate and receptor for SplB. 
PARs (PAR1-4) are a family of 7-transmembrane GPCRs, activated after proteolytic cleavage of the $\mathrm{N}$-terminus at a specific site by extracellular proteases. This event creates a new N-terminal domain, which acts as a tethered ligand that activates the receptor $(64,60)$. The canonical activator, trypsin, cleaves hPAR2 between $\mathrm{R}^{36} / / \mathrm{S}^{37}$ and $\mathrm{K}^{34} / / \mathrm{G}^{35}$, revealing a tethered ligand with the sequence "SLIGKV" $(61,60)$. Similar to trypsin, cockroach E1-E3 and Pen C proteases cleave PAR2 at the canonical cleavage site, $R^{36} / / S^{37}$, whereas neutrophil-derived enzymes cleave PAR2 downstream of this tethered ligand region. For example, proteinase-3 cleaves PAR2 at $\mathrm{V}^{48} / / \mathrm{T}^{49}, \mathrm{~V}^{55} / / \mathrm{E}^{56}, \mathrm{~T}^{57} / / \mathrm{V}^{58}, \mathrm{~V}^{61} / / \mathrm{D}^{62}, \mathrm{D}^{62} / / \mathrm{E}^{63}$, cathepsin-G at $\mathrm{F}^{59} / / \mathrm{S}^{60}, \mathrm{~F}^{64} / / \mathrm{S}^{65}$ and $S^{65} / / A^{66}$, and elastase at $V^{42} / / D^{43}, V^{48} / / T^{49}, V^{53} / / T^{54}, V^{58} / / F^{59}, A^{66} / / S^{67}$ and $S^{67} / / V^{68}(60)$. Cleavage of PAR2 by these neutrophil enzymes are known to trigger signalling responses that are distinct from those elicited by the canonical activator trypsin (64). To determine the SplB cleavage sites on hPAR2, we treated a peptide spanning the $\mathrm{N}$-terminal domain of the trypsin cleavage region with SpIB. We found that SpIB did not cleave the peptide, indicating that SpIB recognition sites are distinct from the trypsin target site as seen for the neutrophil derived enzymes. Previous studies characterizing SplB cleavage specificifity had identified preferred cleavage motifs of SplB as WELQ//Q, WELQ//N and WELQ//G $(65,66)$. While the entire SplB cleavage motif was not identified in the PAR2 $\mathrm{N}$-terminus, a $Q^{27} / / \mathrm{G}$ cleavage site is present upstream of the trypsin cleavage site and needs to be investigated further in future studies as the putative SplB cleavage site on PAR2.

PAR2 can interact intracellularly with multiple heterotrimeric G-proteins to trigger various signaling pathways $(21,20)$. PAR2 activation by trypsin triggers robust cytoplasmic calcium release, which is dependent on $\mathrm{G}_{\alpha_{\mathrm{q} / 11}}$-signaling pathway (59). We observed that SplB cleavage of PAR2 did not result in $\mathrm{Ga}_{\mathrm{q} 11}$-mediated calcium release and ERK phosphorylation ( $\mathrm{pERK}$ ) downstream of PAR2, while trypsin, a known PAR2 activating enzyme, induced robust calcium mobilization (Supplementary Figure 2) and activated pERK. PAR2 can however couple to multiple signalling effectors including $\mathrm{G \alpha}_{12 / 13}, \mathrm{G}_{\alpha_{\mathrm{i} / \mathrm{OB}}}$ and $\beta$-arrestins. Using a BRET assay, we demonstrated that cleavage of PAR2 by SplB triggers recruitment of $G \alpha_{i}, G \alpha_{o B}, G \alpha_{13}$, $\beta$-arrestin1 and -2 . It has been shown that depending on the effector being engaged, PAR2 activation leads to different intracellular signaling cascades influencing transcriptional regulation of specific genes including the induction of proinflammatory cytokines $(60,48)$. It is also know that PARs can elicit distinct responses referred to as "biased agonism," where ligands or proteases of various origins activate the same receptors but induce different signaling responses $(67,53,24)$. Here we identify SpIB as a novel biased activator of PAR2. 
Treatment of primary endothelial cells with SpIB and PAR2-AP lead to proinflammatory cytokine release in a PAR2 dependent manner. The observed cytokine response was completely abolished in the presence of NF- $\mathrm{k} \beta$ inhibitor, indicating that SpIB triggers the PAR2-NF-K $\beta$ axis. Extracellular proteases of various origins activate PAR2 on endothelial cells and induce the production of proinflammatory cytokines and chemokines, the latter involved in the disruption of the endothelial barrier $(68,69)$ by downregulating the expression of VE-cadherin, an essential component of the barrier (9). SpIB induced a similar response in human primary endothelial cells that was characterized by the release of proinflammatory cytokines and a strong reduction of VE-cadherin. Other mechanisms are also possible for PAR2 regulation of the endothelial cytoskeleton. PAR2 activation of the small Rho GTPase Cdc42 is implicated in remodelling of the actin cytoskeleton and exocytosis (70). S. aureus is similarly reported to engage Cdc42 in order to invade human endothelial cells (71). Whether $S$. aureus regulation of Cdc42 involves PAR2 remains to be examined.

Our results unveiled that SpIB induces endothelial barrier disruption in vivo in mice. Therapeutic blockade of SpIB with a monoclonal antibody preserved the barrier integrity. Overcoming the endothelial barrier is crucial for $S$. aureus dissemination and a wide range of virulence factors and proteases secreted by $S$. aureus are reported to induce endothelial barrier dysfunction ( 9 , $43,14,8)$. Here we identified a key virulence factor of $S$. aureus that contributes to barrier disruption. It is plausible that SpIB-induced barrier disruption in vivo is mediated by the disturbance of VE-cadherin homeostasis.

Endothelial dysfunction is also a hallmark of allergic asthma (72), and PAR2 signaling has been implicated in disturbing the endothelial barrier integrity and the development of pathology (63, 9, $27,32,33,29)$. Many allergen-derived proteases mediate endothelial dysfunction via activating PAR2 on mucosal endothelial and epithelial cells (14). Allergens of house dust mite activate PAR2 on multiple cells in the lung (73). Mice deficient for PAR2 or subjected to therapeutic PAR2-blockade displayed a strongly reduced influx of eosinophils in bronchoalveolar lavage fluid (BALF) and lung tissue compared to WT counterparts $(33,74)$. Deficiency of PAR2 protected mice from cockroach allergen-induced airway inflammation and airway hyperresponsiveness (75). We previously demonstrated that administration of SpID in mice induces allergic asthma, which was associated with increased numbers of PAR2-positive infiltrating cells in the lungs, but SpID did not cleave PAR2 (40). It is plausible that SpID-induced type 2 lung inflammation triggered mast cells to release endogenous proteases, which in turn recruited and activated inflammatory cells (macrophages and T cells) in a PAR2 dependent manner. Overall, these data indicated that PAR2 may be an excellent target for development of drugs to limit $S$. aureus 
mediated inflammatory responses. Indeed, the PAR2 negative allosteric modulator AZ3451 in our hands decreased inflammation triggered by SpIB. Additional work with antagonists, particularly those selectively targeting PAR2 signaling pathways such as $G \alpha_{i}$ and $G \alpha_{12 / 13}$ may uncover more effective therapeutics. Antagonists that only block PAR2 coupling to $\mathrm{G} \alpha_{\mathrm{q} / 11}$ are unlikely to be effective in the context of SpIB mediated inflammation.

Taken together, our results clearly show that $S$. aureus SpIB activates endothelial cells via PAR2 and contributes to inflammation and the disruption of the endothelial barrier. This identifies a novel mechanism by which $S$. aureus invades the host.

\section{Acknowledgements}

We thank Vanessa Vau and Sarah Böttcher for their assistance with the immunofluorescence experiments, and Britta Fielitz for providing primary human endothelial cells. This study was supported by Deutsche Forschungsgemeinschaft (DFG), Sonderforschungsbereich (SFB) 914 , project B03 to C.A.R.

\section{Author contributions}

Conceptualization and project design: A.C, R.R, B.M.B, and M.N.D; methodology and performance of experiments: A.C, P.E.T, B.S, L.A.M, and M.N.D; data evaluation: A.C, B.S, S.D.E, C.A.R, R.R, and M.N.D; interpretation of data: A.C, C.A.R, R.R, B.M.B, and M.N.D; writing - original draft preparation: A.C, R.R, B.M.B, and M.N.D; review, comments, and editing: all authors critically reviewed the manuscript. Par2 ${ }^{-/}$mice were provided by B.H.R. Recombinant SplB protein was expressed and purified by M.N. SpIB monoclonal antibody was produced by D.M.M and J.I.

\section{Declaration of interests}

The authors declare no competing interests. 


\section{References}

1. Harris LG, Foster SJ, Richards RG. An introduction to Staphylococcus aureus, and techniques for identifying and quantifying $S$. aureus adhesins in relation to adhesion to biomaterials: review. Eur Cell Mater 2002; 4:39-60.

2. Nasal Carriage of S. aureus Jan Kluytmans et al. 1997.

3. Invasive Methicillin-Resistant Staphylococcus aureus Infections in the United States.

4. Fowler VG, Proctor RA. Where does a Staphylococcus aureus vaccine stand? Clin Microbiol Infect 2014; 20 Suppl 5:66-75.

5. David MZ, Daum RS. Community-associated methicillin-resistant Staphylococcus aureus: epidemiology and clinical consequences of an emerging epidemic. Clin Microbiol Rev 2010; 23(3):616-87.

6. Kazimoto T, Abdulla S, Bategereza L, Juma O, Mhimbira F, Weisser M et al. Causative agents and antimicrobial resistance patterns of human skin and soft tissue infections in Bagamoyo, Tanzania. Acta Trop 2018; 186:102-6.

7. Waness A. Revisiting Methicillin-Resistant Staphylococcus aureus Infections. J Glob Infect Dis 2010; 2(1):49-56.

8. Haslinger-Löffler B, Kahl BC, Grundmeier M, Strangfeld K, Wagner B, Fischer U et al. Multiple virulence factors are required for Staphylococcus aureus-induced apoptosis in endothelial cells. Cell Microbiol 2005; 7(8):1087-97.

9. Karki P, Ke Y, Tian Y, Ohmura T, Sitikov A, Sarich N et al. Staphylococcus aureus-induced endothelial permeability and inflammation are mediated by microtubule destabilization. J Biol Chem 2019; 294(10):3369-84.

10. Bien J, Sokolova O, Bozko P. Characterization of Virulence Factors of Staphylococcus aureus: Novel Function of Known Virulence Factors That Are Implicated in Activation of Airway Epithelial Proinflammatory Response. J Pathog 2011; 2011:601905.

11. Oviedo-Boyso J, Barriga-Rivera JG, Valdez-Alarcón JJ, Bravo-Patiño A, Cárabez-Trejo A, Cajero-Juárez $\mathrm{M}$ et al. Internalization of Staphylococcus aureus by bovine endothelial cells is associated with the activity state of NF-kappaB and modulated by the pro-inflammatory cytokines TNF-alpha and IL-1beta. Scand J Immunol 2008; 67(2):169-76.

12. Internalization S. aureus apoptosis Menzies et al. 1998.

13. Lubkin A, Lee WL, Alonzo F, Wang C, Aligo J, Keller M et al. Staphylococcus aureus Leukocidins Target Endothelial DARC to Cause Lethality in Mice. Cell Host Microbe 2019; 25(3):463-470.e9.

14. Pai AB, Patel H, Prokopienko AJ, Alsaffar H, Gertzberg N, Neumann P et al. Lipoteichoic acid from Staphylococcus aureus induces lung endothelial cell barrier dysfunction: role of reactive oxygen and nitrogen species. PLoS One 2012; 7(11):e49209. 
15. Beaufort N, Corvazier E, Mlanaoindrou S, Bentzmann S de, Pidard D. Disruption of the endothelial barrier by proteases from the bacterial pathogen Pseudomonas aeruginosa: implication of matrilysis and receptor cleavage. PLoS One 2013; 8(9):e75708.

16. Klei LR, Hu D, Panek R, Alfano DN, Bridwell RE, Bailey KM et al. MALT1 Protease Activation Triggers Acute Disruption of Endothelial Barrier Integrity via CYLD Cleavage. Cell Rep 2016; 17(1):221-32.

17. Lin Y, Wozniak JM, Grimsey NJ, Girada S, Patwardhan A, Molinar-Inglis O et al. Phosphoproteomic analysis of protease-activated receptor-1 biased signaling reveals unique modulators of endothelial barrier function. Proc Natl Acad Sci U S A 2020; 117(9):5039-48.

18. Soh UJK, Dores MR, Chen B, Trejo J. Signal transduction by protease-activated receptors. Br J Pharmacol 2010; 160(2):191-203.

19. Jin E, Fujiwara M, Pan X, Ghazizadeh M, Arai S, Ohaki Y et al. Protease-activated receptor (PAR)-1 and PAR-2 participate in the cell growth of alveolar capillary endothelium in primary lung adenocarcinomas. Cancer 2003; 97(3):703-13.

20. Oldham WM, Hamm HE. Heterotrimeric G protein activation by G-protein-coupled receptors. Nat Rev Mol Cell Biol 2008; 9(1):60-71.

21. Oldham WM, Hamm HE. How do Receptors Activate G Proteins? In: Mechanisms and Pathways of Heterotrimeric G Protein Signaling. Elsevier; 2007. p. 67-93 (Advances in Protein Chemistry).

22. Mosnier LO, Sinha RK, Burnier L, Bouwens EA, Griffin JH. Biased agonism of proteaseactivated receptor 1 by activated protein $C$ caused by noncanonical cleavage at Arg46. Blood 2012; 120(26):5237-46.

23. Cabrera-Vera TM, Vanhauwe J, Thomas TO, Medkova M, Preininger A, Mazzoni MR et al. Insights into G protein structure, function, and regulation. Endocr Rev 2003; 24(6):765-81.

24. Zhao $P$, Metcalf $M$, Bunnett NW. Biased signaling of protease-activated receptors. Front Endocrinol (Lausanne) 2014; 5:67.

25. Rohani MG, DiJulio DH, An JY, Hacker BM, Dale BA, Chung WO. PAR1- and PAR2-induced innate immune markers are negatively regulated by PI3K/Akt signaling pathway in oral keratinocytes. BMC Immunol 2010; 11:53.

26. Yee MC, Nichols HL, Polley D, Saifeddine M, Pal K, Lee K et al. Protease-activated receptor-2 signaling through $\beta$-arrestin-2 mediates Alternaria alkaline serine protease-induced airway inflammation. Am J Physiol Lung Cell Mol Physiol 2018; 315(6):L1042-L1057.

27. D'Agostino B, Roviezzo F, Palma R de, Terracciano S, Nardo M de, Gallelli L et al. Activation of protease-activated receptor-2 reduces airways inflammation in experimental allergic asthma. Clin Exp Allergy 2007; 37(10):1436-43.

28. Reed CE, Kita $\mathrm{H}$. The role of protease activation of inflammation in allergic respiratory diseases. J Allergy Clin Immunol 2004; 114(5):997-1008; quiz 1009.

29. Peters T, Henry PJ. Protease-activated receptors and prostaglandins in inflammatory lung disease. Br J Pharmacol 2009; 158(4):1017-33. 
30. Knight DA, Lim S, Scaffidi AK, Roche N, Chung KF, Stewart GA et al. Protease-activated receptors in human airways: upregulation of PAR-2 in respiratory epithelium from patients with asthma. J Allergy Clin Immunol 2001; 108(5):797-803.

31. Miike S, Kita H. Human eosinophils are activated by cysteine proteases and release inflammatory mediators. J Allergy Clin Immunol 2003; 111(4):704-13.

32. Luo W, Wang Y, Reiser G. Protease-activated receptors in the brain: receptor expression, activation, and functions in neurodegeneration and neuroprotection. Brain Res Rev 2007; 56(2):331-45.

33. Davidson CE, Asaduzzaman M, Arizmendi NG, Polley D, Wu Y, Gordon JR et al. Proteinase-activated receptor-2 activation participates in allergic sensitization to house dust mite allergens in a murine model. Clin Exp Allergy 2013; 43(11):1274-85.

34. Day SB, Ledford JR, Zhou P, Lewkowich IP, Page K. German cockroach proteases and protease-activated receptor-2 regulate chemokine production and dendritic cell recruitment. $\mathrm{J}$ Innate Immun 2012; 4(1):100-10.

35. Thammavongsa V, Kim HK, Missiakas D, Schneewind O. Staphylococcal manipulation of host immune responses. Nat Rev Microbiol 2015; 13(9):529-43.

36. Tam K, Torres VJ. Staphylococcus aureus Secreted Toxins and Extracellular Enzymes. Microbiol Spectr 2019; 7(2).

37. Stentzel S, Teufelberger A, Nordengrün M, Kolata J, Schmidt F, van Crombruggen K et al. Staphylococcal serine protease-like proteins are pacemakers of allergic airway reactions to Staphylococcus aureus. J Allergy Clin Immunol 2017; 139(2):492-500.e8.

38. Krysko O, Teufelberger A, van Nevel S, Krysko DV, Bachert C. Protease/antiprotease network in allergy: The role of Staphylococcus aureus protease-like proteins. Allergy 2019; 74(11):2077-86.

39. Paharik AE, Salgado-Pabon W, Meyerholz DK, White MJ, Schlievert PM, Horswill AR. The Spl Serine Proteases Modulate Staphylococcus aureus Protein Production and Virulence in a Rabbit Model of Pneumonia. mSphere 2016; 1(5).

40. Teufelberger AR, Nordengrün M, Braun H, Maes T, Grove K de, Holtappels G et al. The IL33/ST2 axis is crucial in type 2 airway responses induced by Staphylococcus aureus-derived serine protease-like protein D. J Allergy Clin Immunol 2018; 141(2):549-559.e7.

41. Popowicz GM, Dubin G, Stec-Niemczyk J, Czarny A, Dubin A, Potempa J et al. Functional and structural characterization of Spl proteases from Staphylococcus aureus. J Mol Biol 2006; 358(1):270-9.

42. Singh V, Phukan UJ. Interaction of host and Staphylococcus aureus protease-system regulates virulence and pathogenicity. Med Microbiol Immunol 2019; 208(5):585-607.

43. Murphy J, Ramezanpour M, Stach N, Dubin G, Psaltis AJ, Wormald P-J et al. Staphylococcus Aureus V8 protease disrupts the integrity of the airway epithelial barrier and impairs IL-6 production in vitro. Laryngoscope 2018; 128(1):E8-E15. 
44. Stec-Niemczyk J, Pustelny K, Kisielewska M, Bista M, Boulware KT, Stennicke HR et al. Structural and functional characterization of SplA, an exclusively specific protease of Staphylococcus aureus. Biochem J 2009; 419(3):555-64.

45. Jaffe EA, Nachman RL, Becker CG, Minick CR. Culture of human endothelial cells derived from umbilical veins. Identification by morphologic and immunologic criteria. J Clin Invest 1973; 52(11):2745-56.

46. World Medical Association Declaration of Helsinki: ethical principles for medical research involving human subjects. JAMA 2013; 310(20):2191-4.

47. Deinhardt-Emmer S, Rennert K, Schicke E, Cseresnyés Z, Windolph M, Nietzsche S et al. Co-infection with Staphylococcus aureus after primary influenza virus infection leads to damage of the endothelium in a human alveolus-on-a-chip model. Biofabrication 2020; 12(2):25012.

48. Chandrabalan A, Firth A, Litchfield RB, Appleton CT, Getgood A, Ramachandran R. Identification of Proteinase Activated Receptor (PAR) cleaving enzymes in human osteoarthritis knee joint synovial fluids; 2020. ( vol 17).

49. Mihara K, Ramachandran R, Saifeddine M, Hansen KK, Renaux B, Polley D et al. ThrombinMediated Direct Activation of Proteinase-Activated Receptor-2: Another Target for Thrombin Signaling. Mol Pharmacol 2016; 89(5):606-14.

50. Ramachandran R, Mihara K, Chung H, Renaux B, Lau CS, Muruve DA et al. Neutrophil elastase acts as a biased agonist for proteinase-activated receptor-2 (PAR2). J Biol Chem 2011; 286(28):24638-48.

51. Chandrabalan A, McPhillie MJ, Morice AH, Boa AN, Sadofsky LR. N-Cinnamoylanthranilates as human TRPA1 modulators: Structure-activity relationships and channel binding sites. Eur J Med Chem 2019; 170:141-56.

52. Takasaki J, Saito T, Taniguchi M, Kawasaki T, Moritani $Y$, Hayashi $K$ et al. A novel Galphaq/11-selective inhibitor. J Biol Chem 2004; 279(46):47438-45.

53. Thibeault PE, LeSarge JC, Arends D'A, Fernandes M, Chidiac P, Stathopulos PB et al. Molecular basis for activation and biased signaling at the thrombin-activated GPCR proteinase activated receptor-4 (PAR4). J Biol Chem 2020; 295(8):2520-40.

54. Ayoub MA, Pin J-P. Interaction of Protease-Activated Receptor 2 with G Proteins and $\beta$ Arrestin 1 Studied by Bioluminescence Resonance Energy Transfer. Front Endocrinol (Lausanne) 2013; 4:196.

55. Olsen RHJ, DiBerto JF, English JG, Glaudin AM, Krumm BE, Slocum ST et al. TRUPATH, an open-source biosensor platform for interrogating the GPCR transducerome. Nat Chem Biol 2020; 16(8):841-9.

56. Polley DJ, Mihara K, Ramachandran R, Vliagoftis H, Renaux B, Saifeddine M et al. Cockroach allergen serine proteinases: Isolation, sequencing and signalling via proteinaseactivated receptor-2. Clin Exp Allergy 2017; 47(7):946-60.

57. Khandoga AG, Khandoga A, Anders H-J, Krombach F. Postischemic vascular permeability requires both TLR-2 and TLR-4, but only TLR-2 mediates the transendothelial migration of leukocytes. Shock 2009; 31(6):592-8. 
58. Signalling PAR1 Caveolae Russo et al. 2009.

59. Thibeault PE, Ramachandran R. Role of the Helix-8 and C-Terminal Tail in Regulating Proteinase Activated Receptor 2 Signaling. ACS Pharmacol Transl Sci 2020; 3(5):868-82.

60. Heuberger DM, Schuepbach RA. Protease-activated receptors (PARs): mechanisms of action and potential therapeutic modulators in PAR-driven inflammatory diseases. Thromb $\mathrm{J}$ $2019 ; 17: 4$.

61. Loew D, Perrault C, Morales M, Moog S, Ravanat C, Schuhler S et al. Proteolysis of the exodomain of recombinant protease-activated receptors: prediction of receptor activation or inactivation by MALDI mass spectrometry. Biochemistry 2000; 39(35):10812-22.

62. Kumar Vr S, Darisipudi MN, Steiger S, Devarapu SK, Tato M, Kukarni OP et al. Cathepsin S Cleavage of Protease-Activated Receptor-2 on Endothelial Cells Promotes Microvascular Diabetes Complications. J Am Soc Nephrol 2016; 27(6):1635-49.

63. Reed SB, Wesson CA, Liou LE, Trumble WR, Schlievert PM, Bohach GA et al. Molecular characterization of a novel Staphylococcus aureus serine protease operon. Infect Immun 2001; 69(3):1521-7.

64. Adams MN, Ramachandran R, Yau M-K, Suen JY, Fairlie DP, Hollenberg MD et al. Structure, function and pathophysiology of protease activated receptors. Pharmacol Ther 2011; 130(3):248-82.

65. Pustelny K, Stach N, Wladyka B, Dubin A, Dubin G. Evaluation of P1' substrate specificity of staphylococcal SplB protease. Acta Biochim Pol 2014; 61(1):149-52.

66. Dubin G, Stec-Niemczyk J, Kisielewska M, Pustelny K, Popowicz GM, Bista M et al. Enzymatic activity of the Staphylococcus aureus SplB serine protease is induced by substrates containing the sequence Trp-Glu-Leu-GIn. J Mol Biol 2008; 379(2):343-56.

67. Ramachandran R, Mihara K, Mathur M, Rochdi MD, Bouvier M, Defea K et al. Agonistbiased signaling via proteinase activated receptor-2: differential activation of calcium and mitogen-activated protein kinase pathways. Mol Pharmacol 2009; 76(4):791-801.

68. Tielemans B, Stoian L, Gijsbers R, Michiels A, Wagenaar A, Farre Marti R et al. Cytokines trigger disruption of endothelium barrier function and p38 MAP kinase activation in BMPR2silenced human lung microvascular endothelial cells. Pulm Circ 2019; 9(4):2045894019883607.

69. Zhang R, Ge J. Proteinase-Activated Receptor-2 Modulates Ve-Cadherin Expression to Affect Human Vascular Endothelial Barrier Function. J Cell Biochem 2017; 118(12):4587-93.

70. Klarenbach SW, Chipiuk A, Nelson RC, Hollenberg MD, Murray AG. Differential actions of PAR2 and PAR1 in stimulating human endothelial cell exocytosis and permeability: the role of Rho-GTPases. Circ Res 2003; 92(3):272-8.

71. Rauch L, Hennings K, Trasak C, Röder A, Schröder B, Koch-Nolte F et al. Staphylococcus aureus recruits Cdc42GAP through recycling endosomes and the exocyst to invade human endothelial cells. J Cell Sci 2016; 129(15):2937-49.

72. Asosingh K, Weiss K, Queisser K, Wanner N, Yin M, Aronica M et al. Endothelial cells in the innate response to allergens and initiation of atopic asthma. J Clin Invest 2018; 128(7):3116-28. 
73. Gregory LG, Lloyd CM. Orchestrating house dust mite-associated allergy in the lung. Trends Immunol 2011; 32(9):402-11.

74. Asaduzzaman M, Nadeem A, Arizmendi N, Davidson C, Nichols HL, Abel M et al. Functional inhibition of PAR2 alleviates allergen-induced airway hyperresponsiveness and inflammation. Clin Exp Allergy 2015; 45(12):1844-55.

75. Arizmendi NG, Abel M, Mihara K, Davidson C, Polley D, Nadeem A et al. Mucosal Allergic Sensitization to Cockroach Allergens Is Dependent on Proteinase Activity and ProteinaseActivated Receptor-2 Activation. J Immunol 2011; 186(5):3164-72. 


\section{Figure legends}

Figure 1. SplB induces proinflammatory cytokines in vitro. (A) Primary human endothelial cells were left untreated or treated with SplB $(10 \mu \mathrm{g} / \mathrm{mL})$ for $24 \mathrm{~h}$ and the supernatants were analyzed for indicated cytokines by cytokine bead array. Data are mean $\pm S D$ of three independent experiments performed in duplicates.

Figure 2. SpIB cleaves PAR2 and induces biased downstream signaling. (A) nLuchPAR1/2/4-eYFP CHO cells were left untreated (HBSS) or treated with SplB $(5 \mu \mathrm{g} / \mathrm{mL})$ and the PAR cleavage was measured. Data are mean \pm SEM of at least three independent experiments performed in duplicates. (B) PAR2 triggered calcium mobilization was measured in HEK293 cells treated with either trypsin (100 nM) in the presence or absence of YM254890 $(1 \mu \mathrm{M})$, or SpIB (5 $\mu \mathrm{g} / \mathrm{mL})$ or A23187 $(6 \mu \mathrm{M})$. Data are mean \pm SEM of three independent experiments. Recruitment of (C) $\mathrm{Ga}_{12}$ and $\mathrm{Ga}_{13}$, (D) $\mathrm{Ga}_{i 1}$ and $\mathrm{Ga}_{\mathrm{oB}}$ and (E) $\beta$-arrestin-1 and -2, to PAR2 in response to SpIB $(5 \mu \mathrm{g} / \mathrm{mL}$ ) or trypsin (10 or $100 \mathrm{nM}$ ). BRET ratios (eYFP/rluc) were obtained after normalizing to the HBSS buffer condition. Data are mean \pm SEM of at least three independent experiments performed in duplicates. (E) WT or PAR2-KO HEK293 cells were treated with SplB $(5 \mu \mathrm{g} / \mathrm{mL})$ or trypsin $(10 \mathrm{nM})$. The cell lysates were subjected to SDS-PAGE and blotted for total ERK (tERK) or phosphorylated ERK (pERK). Data are mean \pm SEM of three independent experiments performed in duplicates. A and F: Two-way ANOVA was utilized to determine statistical significance, ${ }^{* * *} p<0.001$ (A) and ${ }^{*} p<0.05(\mathrm{~F})$ vs buffer control. A23187: Calcium ionophore; YM254890: $\mathrm{Ga}_{\mathrm{q} / 11}$ inhibitor

Figure 3. SpIB induces IL-6 release via PAR2-NF-k $\beta$ signaling cascade. Primary human endothelial cells (HUVECs) were stimulated with SpIB or PAR2-AP in the presence or absence of inhibitors to PAR2 (F) or Bay11-0782 (G) for $45 \mathrm{~min}$. After $24 \mathrm{~h}$, cell-free supernatants were analyzed for IL-6 by ELISA. Data are mean \pm SD of two independent experiments performed in duplicates or triplicates. G: One-way ANOVA was utilized to determine statistical significance, ${ }^{* *} p<0.0001$ vs buffer, ${ }^{\# \# \#} p<0.01$, SplB vs SplB-Bay11-0782. AP: Activating peptide; Bay11-0782: NF-k $\beta$ signaling inhibitor; iPar2: PAR2-inhibitor

Figure 4. SpIB induces endothelial dysfunction both in vitro and in vivo. (A) Primary human endothelial cell-monolayers were stimulated with PBS or SpIB. The cells were fixed with 4\% PFA before being subjected to immunofluorescence for the indicated markers. Red: VEcadherin, Yellow: ICAM-1. The mean fluorescence intensity (MFI) ratio of VE-Cadherin and ICAM-1 was calculated. Data are mean \pm SD of three independent experiments. (B) Leakage of 
intravenously applied FITC-dextran to the perivascular tissue was analyzed in WT and PAR2 KO animals after intrascrotal stimulation with SpIB with or without pre-treatment with SplBmonoclonal antibody $(m A b)$. Data are mean $\pm S D$ of $4-5$ animals per group. A-B: A t-test was utilized to determine statistical significance, ${ }^{*} p<0.05$ vs buffer $(A)$ and ${ }^{*} p<0.05$ vs SplB + mAb (B).

Supplementary Figure 1. Thrombin cleaves PAR1 and 4, and trypsin cleaves PAR2. (A and C) nLuc-hPAR1/4-eYFP CHO cells were treated with thrombin and (B) nLuc-hPAR2-eYFP CHO cells with treated with trypsin; and the PAR cleavage was measured. Data are mean \pm SEM of at least three independent experiments performed in duplicates.

Supplementary Figure 2. Trypsin induces calcium mobilization. HEK293 cells were treated increasing concentrations of trypsin as indicated. HBSS buffer served as a control. Calcium signaling traces were obtained Fluo-4 NW calcium indicator. Data are mean \pm SEM of three independent experiments.

Supplementary Figure 3. SpIB does not cleave PAR2 at the trypsin cleavage site. Human PAR2 N-terminal domain peptide spanning the tethered ligand region, GTNRSSKGRSLIGKVDGTSHV-NH ${ }_{2}$, was incubated with either trypsin (10 nM) or SpIB (50 $\mu \mathrm{g} / \mathrm{mL}$ ) for 60 minutes at $37^{\circ} \mathrm{C}$. The digestion mixture was analyzed for peptide fragmentation on MALDI-MS. Cleavage sites $(/ /)$ were identified from any additional $\mathrm{m} / \mathrm{z}$ peaks (peptide fragments) observed in the mass spectrum of the enzyme-treated peptide. 
Figure 1
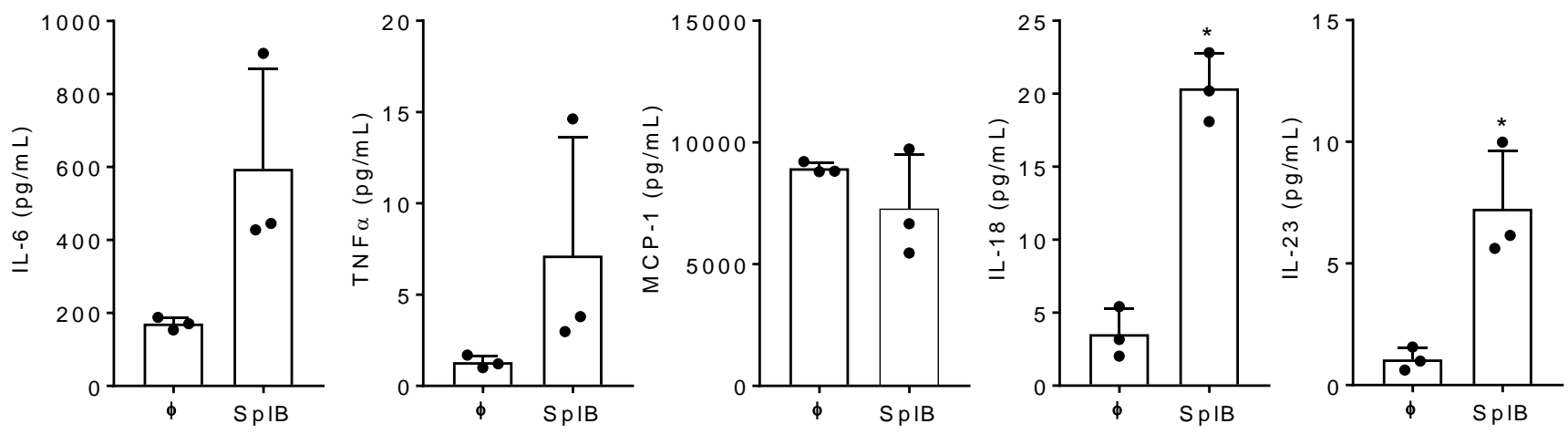
Figure 2

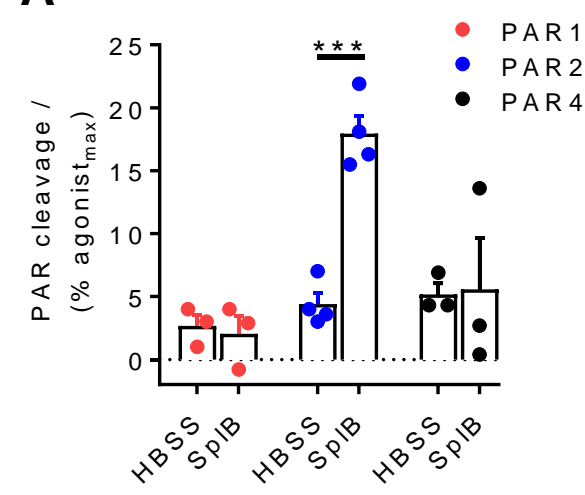

B
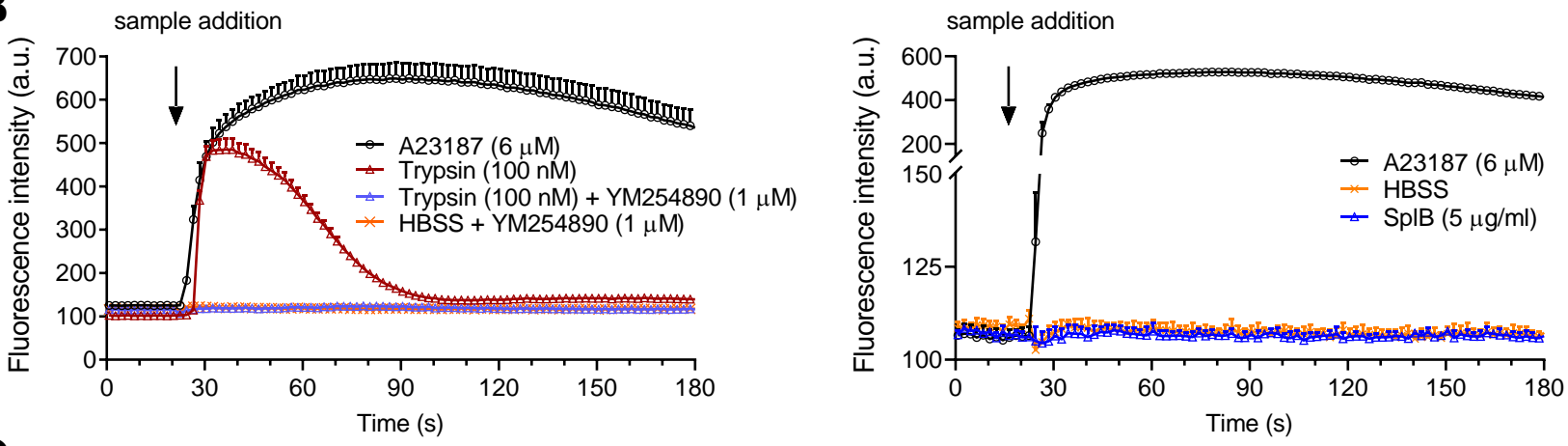

C
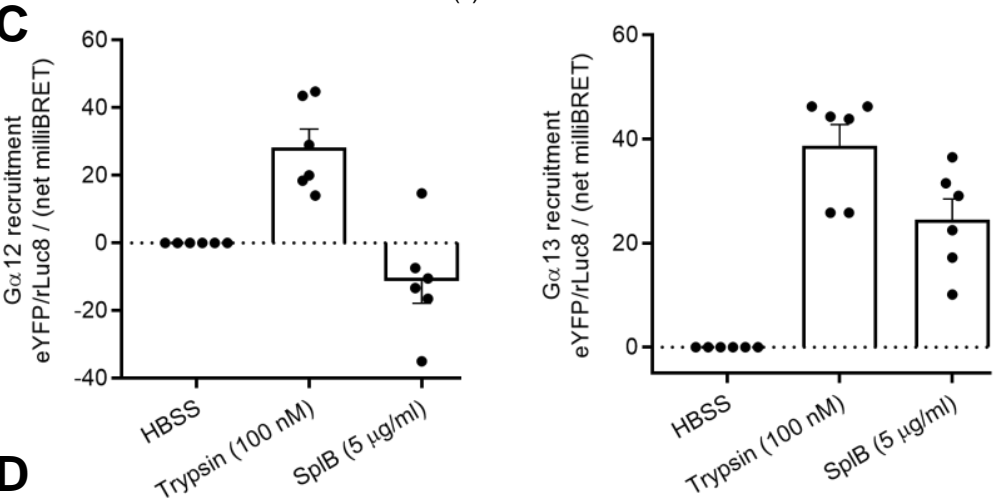

F
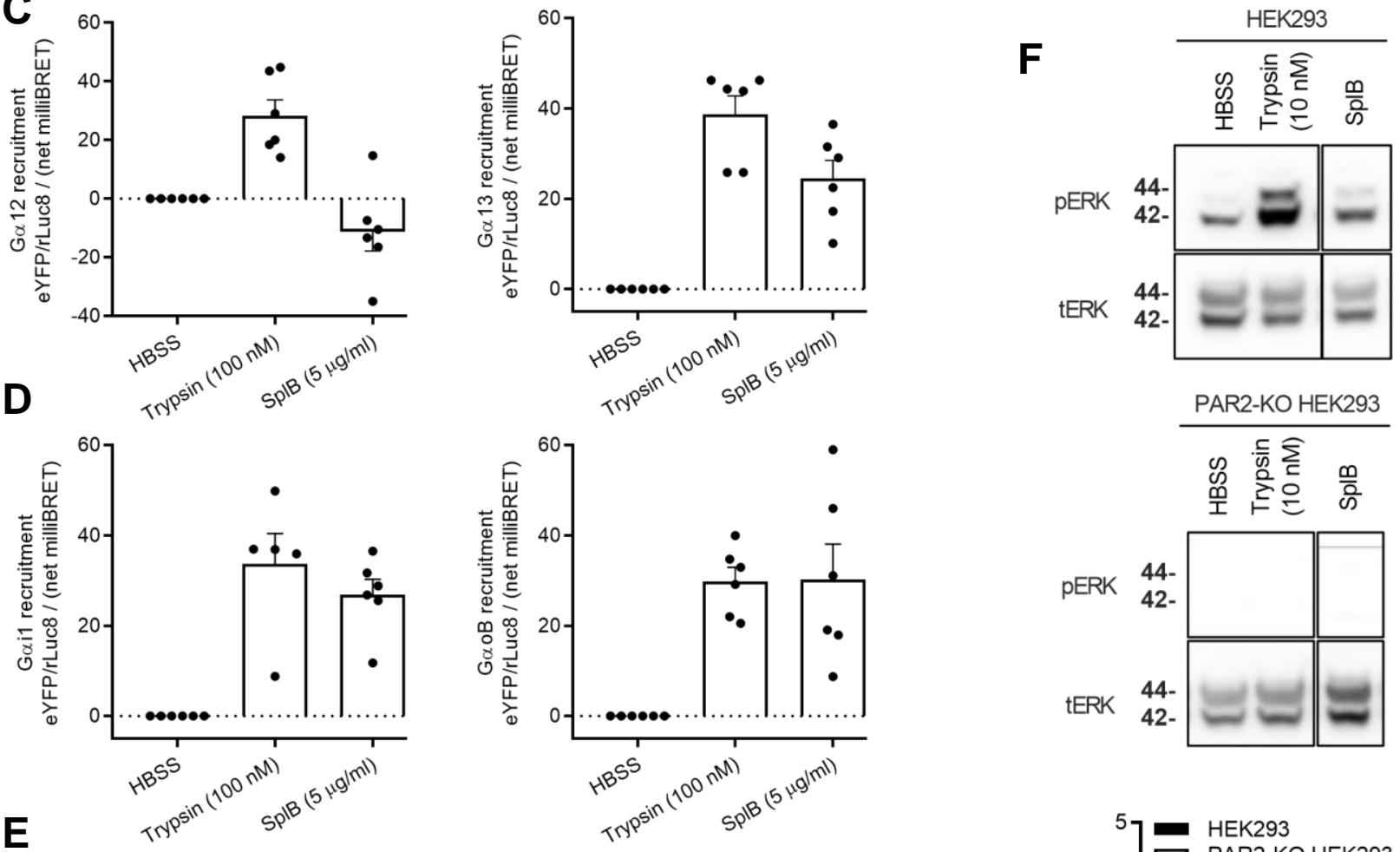

PAR2-KO HEK293 年
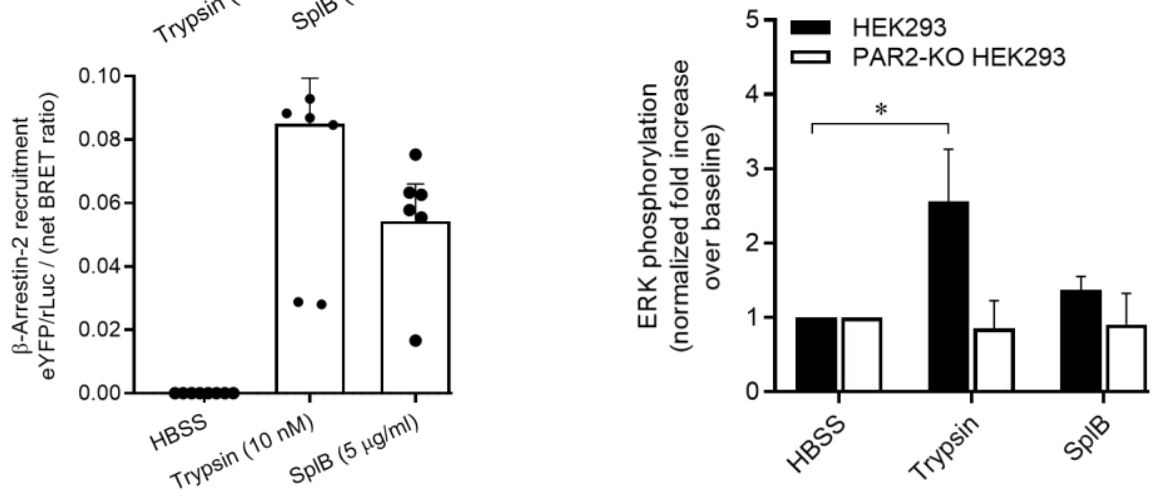
Figure 3
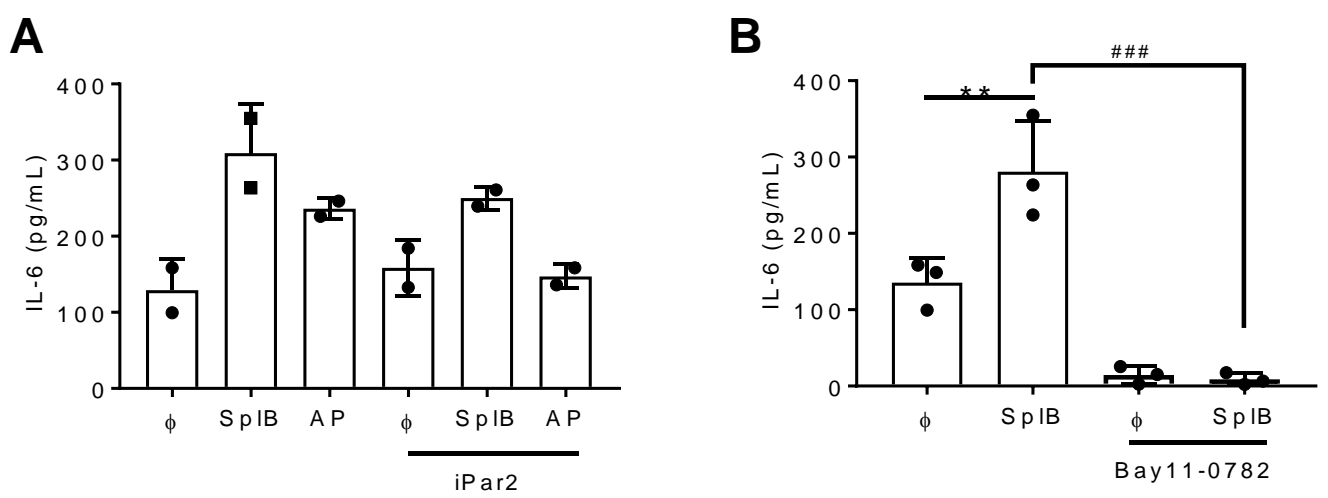
Figure 4

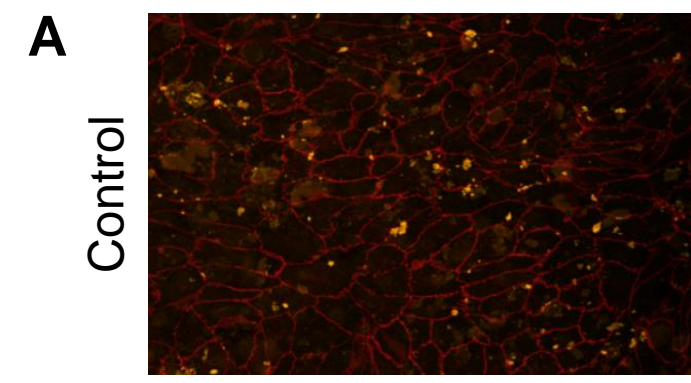

\section{Red: VE-cadherin \\ Yellow: ICAM-1}

B

SplB

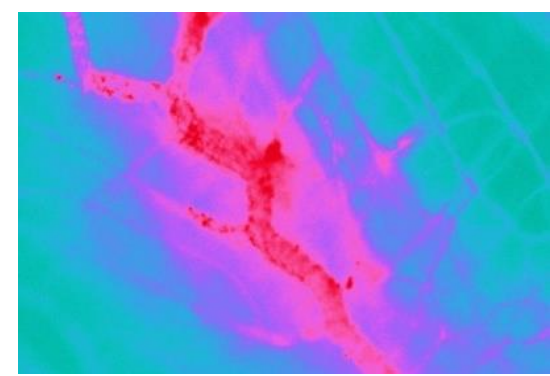

Par2 ${ }^{-}$SplB

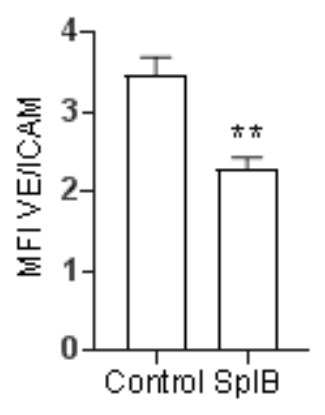

SplB+mAb
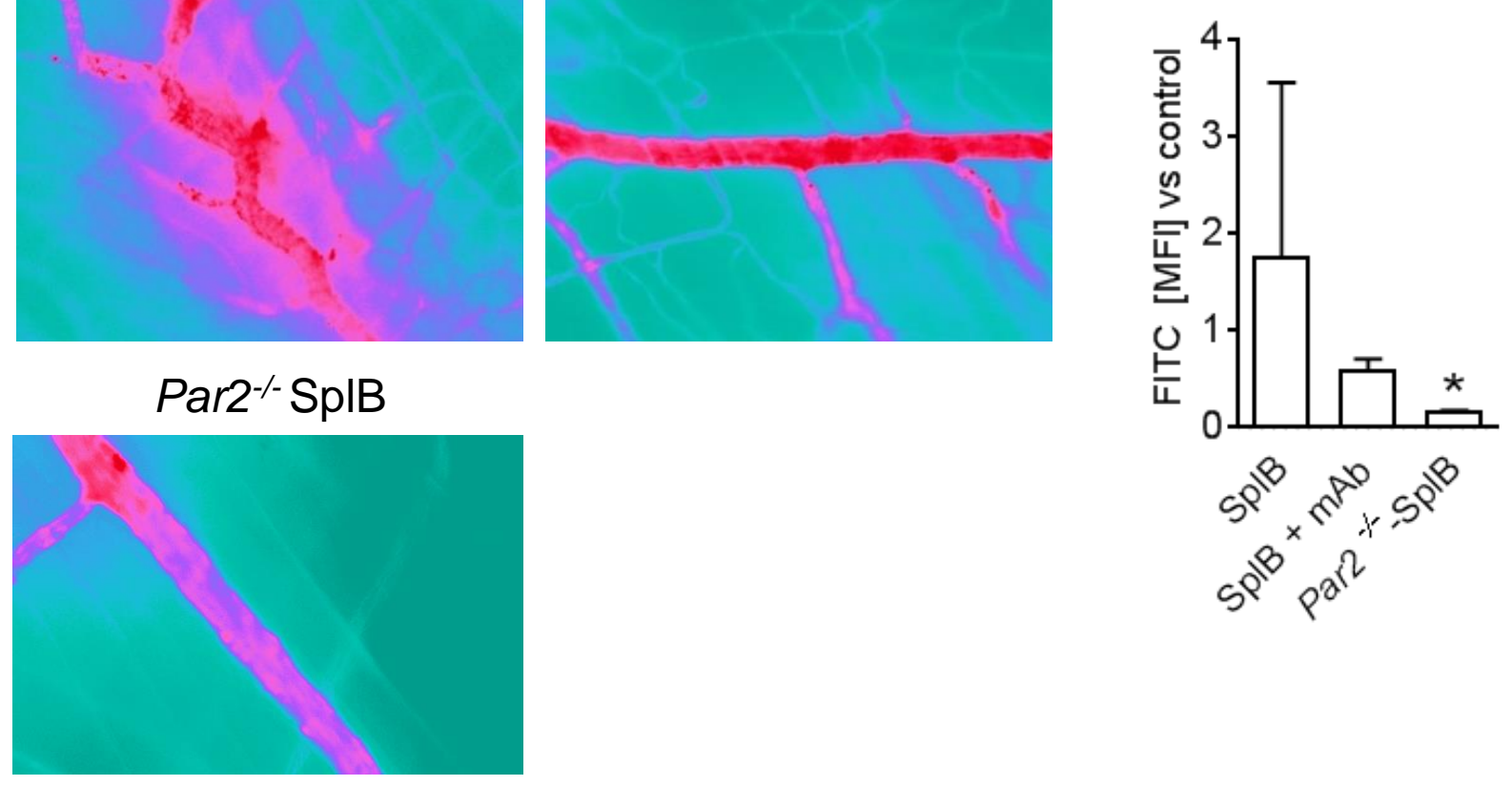


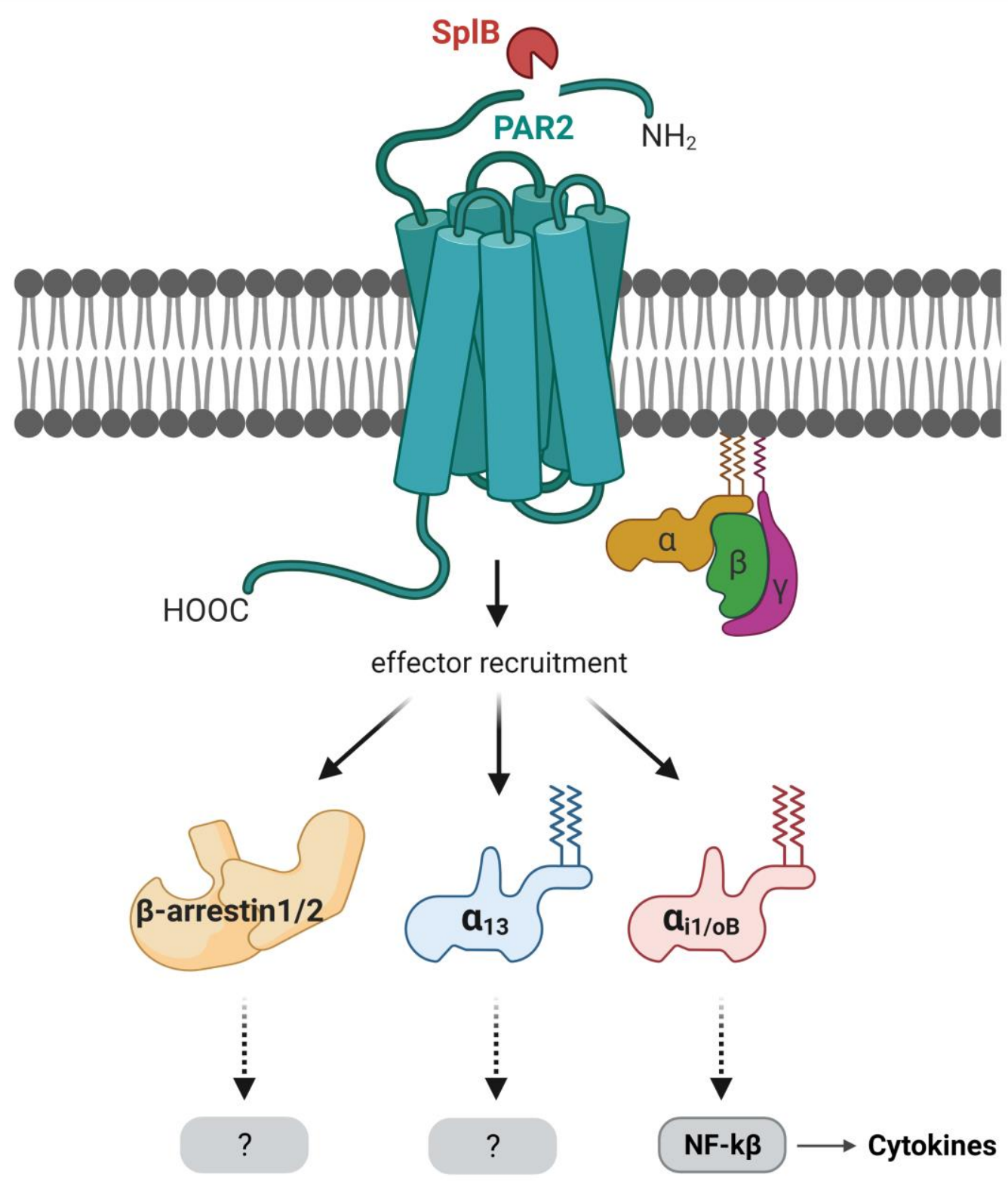

